\title{
Study on seafarers' emotion identification during watch-keeping using bridge simulation
}

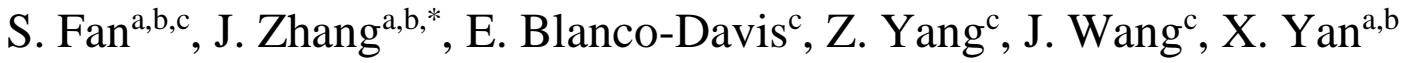 \\ ${ }^{a}$ Intelligent Transport Systems Research Centre, Wuhan University of Technology, China \\ ${ }^{b}$ National Engineering Research Centre for Water Transport Safety, Wuhan, China \\ ${ }^{c}$ Liverpool John Moores University, Liverpool, UK
}

\begin{abstract}
Human factors present one of the essential contributors to maritime accidents, and seafarers' emotion is sensitive to working environment and information inaccessibility. The data collected from 11 experienced seafarers' Self-Assessment Manikin (SAM) questionnaires, is analysed to investigate the impact of their emotions during watch-keeping in a bridge simulator. SAM scale rating questionnaires are received separately after two sections, emotion calibration and recognition. The emotion is induced and identified in the calibration section. In the recognition, emotion is self-rated after the crew-qualified test and the Support Vector Machine (SVM) model is used for classification. The results indicate that SVM can effectively identify the emotions with a precision of $72.73 \%$. Seafarers' emotion in maritime operations affects their behaviour and decisionmaking. The overall positive emotion identified by SAM rating does not mean positive effect on sailing, while negative emotion identified by SAM rating does not lead to negative behaviour.
\end{abstract}

KEYWORDS: Human factors, emotion, bridge simulator, Self-Assessment Manikin, Support Vector Machine

\section{INTRODUCTION}

Nowadays, more than three-quarters of the world trade cargoes in terms of volume are accomplished by shipping (Grech et al., 2008). Shipping contributes to the increase of awareness on transport safety in maritime. Surveys (Ren et al., 2008) show that $75-96 \%$ of maritime accidents are fully or partially caused by human and organisational errors. There has been an overwhelming understanding since 1993 when the USCG reported that human errors had been the essential cause of approximately $80 \%$ of maritime accidents and near misses over the past decades (Grech et al., 2008). Moreover, out of nearly $62 \%$ of pollution and maritime accidents over the past years ( $\mathrm{Er}$ and Celik, 2005), human factors result in $30 \%$ of deck officer error, $7 \%$ of shore-based personnel error, $2 \%$ of engine officer error, $8 \%$ of pilot error. It reveals that human factors are not the direct cause of the accident, but they are the beginning of a considerable incident or catastrophe by trigging following chain events.

In this regard, it is meaningful to investigate human factors in ship bridge as it is closer to the root causes of maritime accidents. One of the earliest initiatives was fired up by accidents caused by a typical radar-assisted collision (Grech et al., 2008). In 1956, the collision between the two passenger ships Andrea Doria and the Stockholm was one example. The root causes of the accident were related to the ship bridge. It is demonstrated that much attention should be paid to human factors and the bridge. Consequently, it causes some interest in the area of bridge design and cognition, both in Europe and the United States. Nowadays, the bridge has become more automated. Automation is often highlighted because it has been overwhelmingly understood that it would reduce the involvement of crew, so far as to reduce human workload and human errors, and increase efficiency. However, as demonstrated by the grounding of Royal Majesty (the Panamanian passenger ship grounded on Rose and Crown Shoal about 10 miles east of Nantucket Island, Massachusetts on June 10, 1995) as well as evidenced by other research results (Lutzhoft and Dekker, 2002), automation has a prospecting expectation of human work and safety, which cannot simply replace human work thoroughly. Fewer crew numbers do not lead to less workload. There exists increased mental workload affecting situation awareness (Aguiar et al., 2015). In this regard, automation in the bridge creates new error pathways, especially resulting from human errors, deficiencies in mission shifts, and postpone chances to correct errors in the system further into the future. It is noteworthy that the 
bridge plays an essential role in the success and failure of navigation, as well as human errors research.

In the amendments of Seafarers' Training, Certification and Watchkeeping (STCW) Code in 1995, human error was classified in three major taxonomies. They are operational-based, management-based, and the combination of the two. For quantitative assessment of shipping accidents, Celik and Cebi (2009) generated a Human Factors Analysis and Classification System (HFACS) based on a Fuzzy Analytical Hierarchy Process (FAHP), to identify human errors in shipping accidents. In line with the HFACS, as well as Reason's Swiss Cheese Model and Hawkins' SHEL model, Chen et al. (2013) proposed HFACS for a Maritime Accidents (HFACS-MA) model to measure the Human and Organisational Factors (HOFs). Soner et al. (2015) combined Fuzzy Cognitive Mapping (FCM) and HFACS to generate a proactive model in fire prevention modelling onboard ships. Chauvin et al. (2013) found that most collisions were due to decision errors by a modified HFACS model in collisions reported by the Marine Accident and Investigation Branch (UK) and the Transportation Safety Board (Canada). Meanwhile, the accidents were also associated with poor visibility and evidence deficiencies of the socio-technical system (technical environment, the condition of operators, leadership level, and organisational level) (Chauvin et al., 2013). In that way, cognition and error in accidents attract research attention as well.

Quite a number of studies exist on human reliability to define human performance in accidents and estimate human failure probabilities (Yang et al., 2013, Yoshimura et al., 2015, Yang and Wang, 2012). Akyuz and Celik (2015) adopted Cognitive Reliability and Error Analysis Method (CREAM) to assess human reliability along with the cargo loading process, and Akhtar and Utne (2015) used it to study common patterns of interlinked fatigue factors. It was illustrated that "inattention", "inadequate procedures", "observation missed", and "communication failure" were related to fatigue factors that influenced the human cognitive processes in accidents. The bridge team should be trained to recognise fatigue and exercise caution related to the fatigue factors. Moreover, Hetherington et al. (2006) divided human factors into fatigue, stress, health, situation awareness, teamwork, decision-making, communication, automation, and safety cultural diversity.

Among them, the emotion factor of the crew is vulnerable to working space, inaccessible information sources, and communication. Their negative emotions are mainly related to irritability, tension, instability, depression, and burnout with periodic changes. From this perspective, Liu et al. (2016b) proposed an EEG (Electroencephalogram) system in bridge simulation to monitor officers' workload and pressure. It was one of the earliest studies on seafarer's psychological response using bridge simulators. However, the relation with psychological response and seafarers' performance was not demonstrated. For quantification of the crew emotion, this system also took into account monitoring emotion, emotional stress, and environmental stress (Liu et al., 2016a). It identified the emotion of cadets in the bridge simulator supervised by EEG, but not related to human errors neither. Geethanjali et al. (2017) detected and recognised the human emotion using Self-Assessment Manikin (SAM) rating. The statistical analysis revealed the emotion identification differences between several groups. Hence, seafarers' emotion identification should be further studied by better incorporating psychological knowledge.

This study is conducted to identify the emotion in the bridge by SAM rating questionnaires, and classify the emotion in a Support Vector Machine model by use of bridge simulators. It would benefit the crew training aiming at navigational safety and improve the watch-keeping while sailing. The remainder of paper is organized as follows: In Section 2, the methodologies of this study are described, including SAM and SVM methods. The experiment design and procedures are illustrated in Section 3. The result and discussion are presented in Section 4. Finally, the conclusion is given in Section 5.

\section{METHODOLOGY}

\subsection{Self-Assessment Manikin (SAM)}

In this paper, the nine-point scale in Self-Assessment Manikin (SAM) (Bradley and Lang, 1994) (Bradley and Lang, 2007) is used to describe pleasure, arousal, and dominance in response to the stimuli. Figure 1 shows the questionnaire that the test subjects need to complete after the experiments, reflecting on their subjective feelings during the assessment.

The scoring measures the pleasure, arousal, and dominance associated with the stimuli. The first SAM scale is the happy/unhappy scale, which ranges from a smile to a frown. The second scale is the excited/calm scale, which ranges from left to right. The last dimension is the controlled/In-control dimension. The left end of the scale represents the feeling of completely controlled and influenced. The right end of the scale is the feeling of completely controlling, important, and dominant.

The SAM methodology reveals the specific feature of a test subject's certain emotion, as the emotion is a subjective variable. This method quantifies the emotion in specific time and condition. The experiment is recorded by the audio for each test subject. After the qualified test, comments on the performance of seafarers from the experts is recorded by audio, and the test subjects are given a result of pass or not pass. 
1. SAM rating

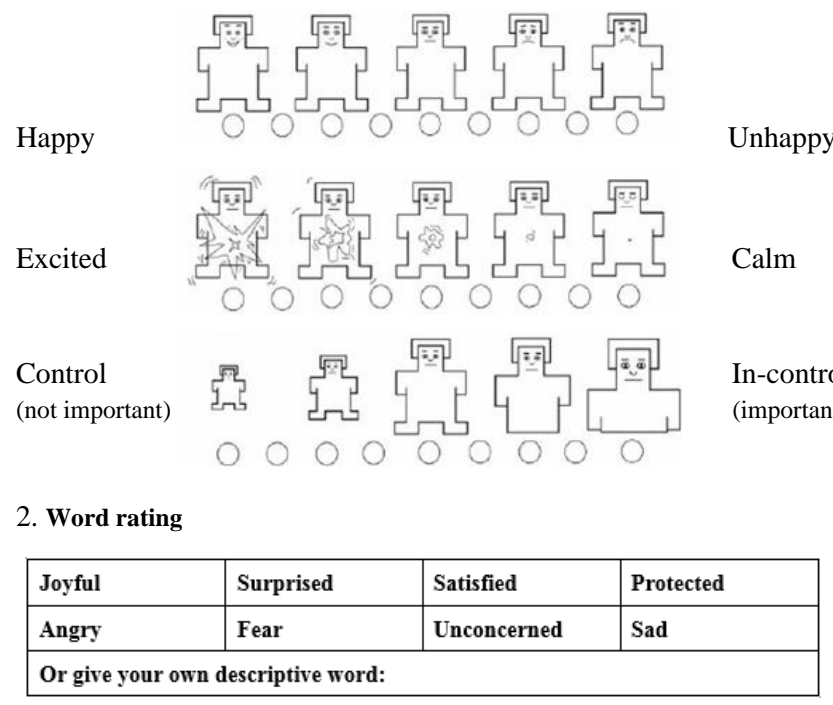

Figure 1. The questionnaire of emotion with SAM scale on a nine-point rating (Liu et al., 2016a)

\subsection{Support Vector Machine (SVM)}

In this study, there are two sorts of emotion categories: positive emotion and negative emotion. The Support Vector Machine (SVM) is used to identify the emotion category for the tested seafarers. SVM is a supervised learning model with associated learning algorithms that analyse data used for classification and regression analysis. As shown in Figure 2 , there are two kinds of sets, type "•" and type " $\bullet$ ". The SVM method finds an optimised hyperplane (e.g. a line defined by "w", "b"), calculating the $w$ and $b$ to maximise the margin while still separating the points (primal form). $C$ is a cost function, which is $C=\max \left(0,1-y_{i}\left(\vec{w} \cdot \vec{x}_{i}-b\right)\right)$ (For data on the wrong side of the margin, $C$ is proportional to the distance from the margin), $\xi_{i}$ is the smallest non-negative number satisfying $\mathrm{y}_{i}\left(w \cdot x_{i}-b\right) \geq 1-\xi_{i}$ :

$$
\begin{aligned}
& \min \frac{1}{l} \sum_{i=1}^{1} \xi_{i}+C\|w\|^{2} \\
& \text { s.t }\left\{\begin{array}{l}
\mathrm{y}_{i}\left(w \cdot x_{i}-b\right) \geq 1-\xi_{\mathrm{i}} \\
\xi_{\mathrm{i}}>0
\end{array} i=1,2, \cdots, l\right.
\end{aligned}
$$

In this study, these points are described in three dimensions illustrated in SAM as pleasure, arousal, and dominance. As the emotion is a subjective variable, the SVM uses the feature of a certain emotion in calibration to generate the classifier. Using the classifier training by SVM, emotion in the qualified test of seafarers is identified by the three-dimensional description questionnaire. Specifically, a $33 \times 3$ matrix is generated as input, among which " 33 " represents " $11 \times 3$ " questionnaires, " 3 " defines three types of emotion dimensions. In addition, the output is a $33 \times 1$ matrix. The group of first 22 samples is the training set while the group of last 11 samples is the test set. After normalisation, the optimal parameters in the
SVM is searched by cross-validation. The kernel function of the model is calculated. The result of identification of emotion taxonomy can be calculated.

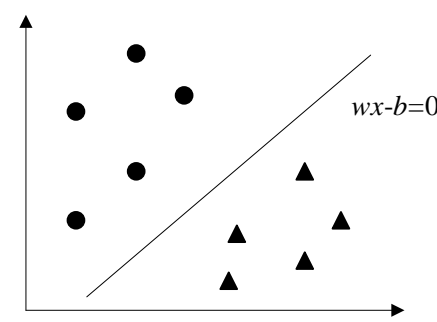

Figure 2. The Support Vector Machine theory

\section{EXPERIMENT}

\subsection{Test subject selection}

Seafarers from different companies who were taking the captain and first officer qualification examinations were recruited to be involved in this study. There were 11 exams scheduled in two days. Each exam tested one participant who acted as a captain in a four-person exam group. All subjects were in good health without head injuries. They have 7.7 years of experience at sea on average, as they present a common emotional response during sailing when compared to beginners or cadets. The test subjects range from 26-38 years old, with the average of 31.9 years old. They are all males. These seafarers attended these experiments as volunteers. The last also demonstrates that they could quit the experiments whenever they changed their minds. Based on this agreement, the calibration part of this study was conducted before the crew-qualified exam, and the test part was carried out after the whole exam. The test subjects were in bridge simulator room, while the staffs were in control room providing scenarios to subjects (Figure 3a, $3 b)$.

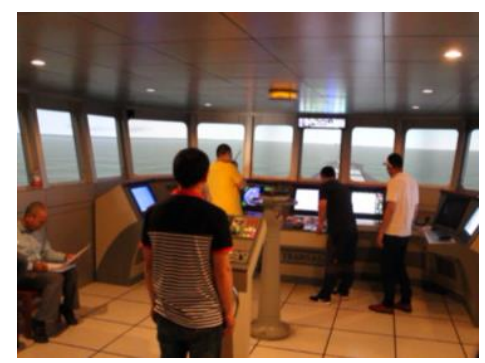

(a) Test subjects in simulator room

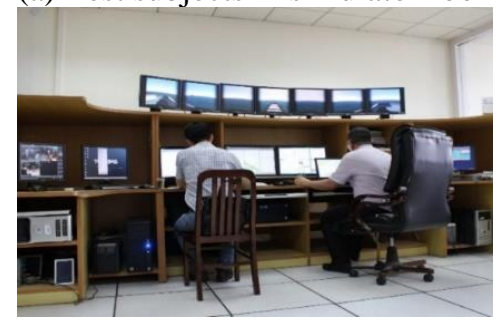

(b) Staff in control room

Figure 3. The test subjects and staffs in control room 


\subsection{Stimuli selection}

The role of "captain" in four seafarers during the exam was selected as an independent sample. The rating of their perceived emotion for each stimulus presented uses a SAM scale. In view of this, IADS database was used as the stimulus with two categories (pleasant and unpleasant). It was presented for the first time, and all the test subjects in this study were not aware of the clips prior to the experiment.

\subsection{Experimental protocol}

The experiment was conducted by SAM scale rating questionnaires received separately after two sections, which are emotion calibration and recognition respectively. In calibration, two types of emotions were induced by the International Affective Digitized Sounds (IADS) methodology, developed by the National Institute of Mental Health Center for the Study of Human Emotion. Every test subject was given by listing to sound clips from IADS with eyes closed in case of blink interrupts. In the calibration part, emotion 1 began with 5 seconds silence to calm down, and 10 seconds for one category of emotion stimulus, and then the SAM rating was carried out. After that, another category of emotion 2 repeated. This section aimed to calibrate emotion for each subject. In other words, the specific feature or standard of personal emotion type was obtained.

In the test part, the subjects filled the questionnaires after at least 30 minutes' exam in the bridge simulator. Figure 4 demonstrates the process of the experiment.

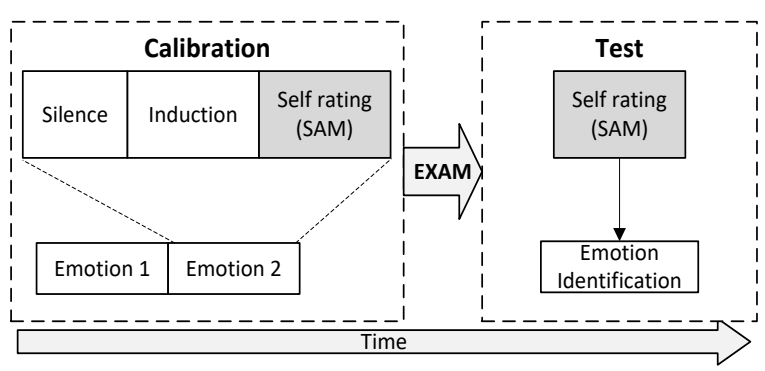

Figure 4. Experimental protocol

\subsection{Statistical analysis}

As the subjective rating for the emotion questionnaire was not normally distributed, the non-parametric test is conducted. The sound clips of the IADS database are considered as independent variables; the pleasure, arousal, and dominance are considered as dependent variables. The correlation between valance and dominance within subjects is calculated using Spearman's correlation (Geethanjali et al., 2017).

\section{RESULT AND DISCUSSION}

\subsection{Descriptive Statistics}

This study collects $22(11 \times 2)$ calibration questionnaires and 11 test questionnaires reflecting 11 seafarers' emotions. Table 1 demonstrates descriptive statistics for seafarers in this research, while Table 2 reveals the statistics in the IADS ( $2^{\text {nd }}$ edition) database. There is correlation coefficient below in Table 3 , and the correlation is significant at the 0.01 level. The clip sounds 105 represents negative emotion, while 220 represents positive emotion in this study. The letter "p", "a", and "d" represent "pleasure", "arousal", "dominance" respectively, and " $\mathrm{t}$ " means test emotion. The majority of the mean value of this study is approximately coincidental with the mean value of the IADS, except for the pleasure dimension in negative emotion. The distinction is also revealed in the questionnaires. Notes state that some of them do not make sense of the meaning of the first clip. Therefore, the neutral feeling with rating 5 is given by them.

\subsection{Emotion identification}

After collecting the emotion data from seafarers by SAM questionnaires, SVM is used to identify the emotion category during watch-keeping. Overall, 11 samples consist of $33 \times 3$ matrix of emotion description, and $33 \times 1$ matrix of emotion labels. The former 22 pieces are from the calibration part as a training set for SVM, and the later 11 pieces are from the test part as a test set. From these perspectives, the SVM model is proposed to find a hyperplane that divides the test set into two kinds of emotion categories. Figure 5 is the result of the test classification with the accuracy of $72.73 \%$, where " 1 " represents negative emotion, and " 2 " means positive emotion. The kernel function of this model is calculated in the way that " $-t=2$ " represents kernel type is radial basis function: exp ($\left.\gamma^{*}\left|x-x^{\prime}\right|^{2}\right)$; “ $-c=776.0469$ " represents cost parameter $C$; “- $\mathrm{g}=0.0068012$ " represents $\gamma$ in kernel function.

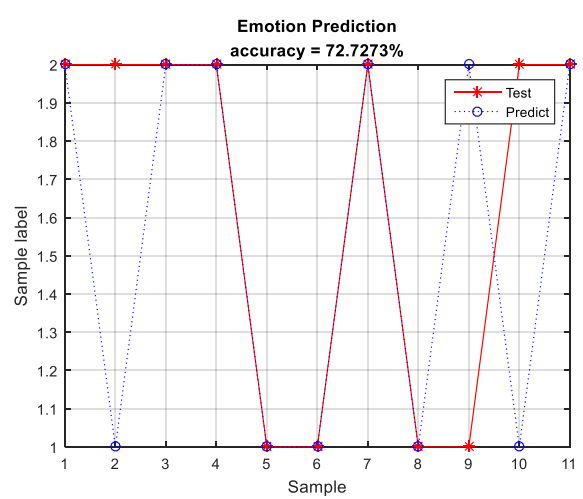

Figure 5. Emotion identification by using the SVM: Accuracy = $95.4545 \%$ (21/22) (training); Accuracy $=72.73 \%$ (8/11) (test) 
Table 1. Statistics of seafarers in the research

\begin{tabular}{lllll}
\hline & Min. & Max. & Mean & SD \\
\hline $105 \mathrm{p}$ & 1 & 9 & 4.82 & 2.601 \\
$105 \mathrm{a}$ & 1 & 7 & 4.18 & 2.272 \\
$105 \mathrm{~d}$ & 1 & 8 & 5.18 & 2.523 \\
$220 \mathrm{p}$ & 3 & 9 & 8.09 & 1.814 \\
$220 \mathrm{a}$ & 1 & 8 & 5.27 & 2.195 \\
$220 \mathrm{~d}$ & 3 & 9 & 6.36 & 1.912 \\
tp & 3 & 9 & 5.73 & 1.679 \\
ta & 1 & 7 & 4.64 & 2.063 \\
td & 1 & 9 & 6.00 & 2.449 \\
\hline
\end{tabular}

$* \mathrm{p}$ - pleasure, a - arousal, $\mathrm{d}$-dominance.
Table 2. Statistics in the IADS ( $2^{\text {nd }}$ Edition $)$

\begin{tabular}{lll}
\hline & Mean & Std. Deviation \\
\hline $105 \mathrm{p}$ & 2.88 & 2.14 \\
$105 \mathrm{a}$ & 6.40 & 2.13 \\
$105 \mathrm{~d}$ & 3.8 & 2.17 \\
$220 \mathrm{p}$ & 7.28 & 1.91 \\
$220 \mathrm{a}$ & 6.0 & 1.93 \\
$220 \mathrm{~d}$ & 5.99 & 1.88 \\
\hline
\end{tabular}

Table 3. Correlation coefficient

\begin{tabular}{llll}
\hline & Pleasure & Arousal & Dominance \\
\hline Negative & 1.000 & -.210 & .043 \\
Positive & 1.000 & .321 & -.068 \\
Test & 1.000 & -.480 & -.742 \\
\hline
\end{tabular}

Table 4. Comments from self-evaluation and third party

\begin{tabular}{|c|c|c|c|c|}
\hline \multirow{2}{*}{ ID } & \multicolumn{2}{|c|}{ Emotion } & \multirow{2}{*}{ Self-evaluation } & \multirow{2}{*}{ Third party } \\
\hline & SR & SVM & & \\
\hline 1 & $P$ & $\mathrm{P}$ & $\begin{array}{l}\text { Untimely watch keeping in poor visibil- } \\
\text { ity } \\
\text { Wrong operation sequence } \\
\text { Too late to realise poor visibility }\end{array}$ & $\begin{array}{l}\text { Operate in incorrect sequence } \\
\text { when stopping }\end{array}$ \\
\hline 2 & $P$ & $\mathrm{~N}$ & $\begin{array}{l}\text { Speed control problem } \\
\text { Inaccurate report in time }\end{array}$ & unconcerned watch keeping \\
\hline 3 & $P$ & $\mathrm{P}$ & $\begin{array}{l}\text { Anxious when collision } \\
\text { Wrong decision making (collision at ship } \\
\text { body instead of bow) }\end{array}$ & $\begin{array}{l}\text { Not fulfil the Convention on the } \\
\text { International Regulations for } \\
\text { Preventing Collisions at Sea } \\
\text { (COLREGs) }\end{array}$ \\
\hline 4 & $\mathrm{P}$ & $\mathrm{P}$ & $\begin{array}{l}\text { Tension during ship encounter } \\
\text { Response too late } \\
\text { Unfamiliar with navigation device }\end{array}$ & $\begin{array}{l}\text { Mistake sail with the current for } \\
\text { sail against the current } \\
\text { Not fulfil COLREGs } \\
\text { Too panic when strand }\end{array}$ \\
\hline 5 & $\mathrm{~N}$ & $\mathrm{~N}$ & $\begin{array}{l}\text { Speed control problem } \\
\text { Not enough communication } \\
\text { Not stop timely }\end{array}$ & $\begin{array}{l}\text { Wrong decision making of the } \\
\text { captain } \\
\text { Manoeuvring inappropriate }\end{array}$ \\
\hline 6 & $\mathrm{~N}$ & $\mathrm{~N}$ & $\begin{array}{l}\text { Speed control problem } \\
\text { Course deviation }\end{array}$ & $\begin{array}{l}\text { Not enough communication } \\
\text { Not enough cooperation not } \\
\text { enough }\end{array}$ \\
\hline 7 & $\mathrm{P}$ & $\mathrm{P}$ & $\begin{array}{l}\text { Late report in emergency } \\
\text { Unconcerned } \\
\text { Inappropriate manoeuvring }\end{array}$ & $\begin{array}{l}\text { Wrong manoeuvring } \\
\text { Too high speed } \\
\text { Course deviation }\end{array}$ \\
\hline 8 & $\mathrm{~N}$ & $\mathrm{~N}$ & Not familiar with rudder failure & $\begin{array}{l}\text { Slow speed affect steering } \\
\text { Failure to meet a contingency }\end{array}$ \\
\hline 9 & $\mathrm{~N}$ & $\mathrm{P}$ & $\begin{array}{l}\text { Not switch on navigation lights when } \\
\text { starting fog }\end{array}$ & $\begin{array}{l}\text { Not on-time watch keeping } \\
\text { Too large deflection angle }\end{array}$ \\
\hline 10 & $P$ & $\mathrm{~N}$ & $\begin{array}{l}\text { Unfamiliar with navigation environment } \\
\text { Not report the collision on time }\end{array}$ & $\begin{array}{l}\text { Unfamiliar with navigation de- } \\
\text { vice } \\
\text { Ignore environment when re- } \\
\text { porting } \\
\text { Failed to fulfil COLREGs }\end{array}$ \\
\hline 11 & $\mathrm{P}$ & $\mathrm{P}$ & Anxious when getting hurt & $\begin{array}{l}\text { Speed control problem } \\
\text { Irregular language }\end{array}$ \\
\hline
\end{tabular}


The emotion identifications by questionnaire from test subject and the SVM methodology are presented in Table 4, where " $\mathrm{P}$ " represents positive and "N" represents negative. More specifically, the self-rating emotions of subject 2 and 10 are positive emotions but were predicted as negative emotions. The self-rating emotion of subject 9 is negative while it was predicted as positive. All the others have the same results between self-rating and SVM.

\subsection{Human performance}

The comments on the examination for each test subject are further analysed to investigate if negative emotion identified by SAM scale questionnaire affects human errors and human performance. Meanwhile, the comments from experts as an inevitable process of the qualified exam are collected by audios. This part took place after the whole sessions, beginning with summarised comments from self-evaluation and third party, and ending in experts' comments.

According to the self-evaluation from the subjects and expert comments after the qualification exam, it is common to demonstrate that the human emotion emerging during watch-keeping affects ship manoeuvring, concentration, response to an emergency, and decision-making.

For example, test subject 1 was not able to concentrate on watch-keeping in poor visibility when sailing, which made him incapable of observing the crew onboard falling into the water. Moreover, a further step to eliminate the hazards they encountered was to stop in accurate and timely operation sequence. The test subjects 2 and 7 had the same result as unconcerned when encountering collision scenarios in poor visibility, resulting in a delayed report and operational problem. As a result, subject 2 reported inaccurately in collision scenario and subject 7 had course deviation. There was obvious anxiety when collision occurred as subject 3 demonstrated, causing not fulfilling COLREGs (International Regulations for Preventing Collisions at Sea). Subject 11 just became anxious when the crew got hurt, causing the irregular use of language and inappropriate manoeuvring. Subject 4 had tension emotion when the encounter happened and panic emotion during strand, which caused several mistakes, as shown in Table 4. In addition, subjects 4 and 10 had physiological problems because they were unfamiliar with the device. They were not fulfilling COLREGs.

From the above emotion problems existing in test subjects $1,2,3,4,7,10,11$, all of them rated overall positive emotion after the sessions. However, the subjects who rated a negative emotion did not reveal apparent emotion interruption on performance. From this perspective, overall positive emotion identified by SAM rating does not mean positive effect on the sailing, while negative emotion identified by SAM rating does not lead to negative behaviour. Emotion rating through subjective judgement presents the overall feeling after the examination, whereas human errors occur at certain instant point. They are not matched well. Moreover, the subjects may hide or ignore their true feelings when the mission is well done, and the questionnaires filled after the examination depend more on the result of the scenario completion than the process.

\section{CONCLUSION}

Seafarers' emotion exists when sailing. It emerges during watch-keeping and could jeopardise the performance and decision-making of seafarers. When an emergency happens, there are requests for the timely report and accurate operation on ships. This study utilised SAM rating scales of 11 test subjects to establish a classification model. The training model is studied by SVM classifier with an accuracy rate at $72.73 \%$. The results concerning officers' emotion in a bridge simulator test reveal that seafarers' emotion in maritime operations affects their behaviour, as well as the possibility of errors in decision-making. In addition, there is no strong correlation between emotion modes identified and behavioural consequences. The overall positive emotion identified by SAM rating does not mean positive effect on sailing, while negative emotion identified by SAM rating does not lead to negative behaviour.

This study does not reveal the accurate in-time response, as the rating is done after the examination. Moreover, some seafarers may hide or ignore their true feelings in the questionnaire after the exam if emergency problems are solved properly in scenarios. Thus, the relations between emotion and human errors are complex, and need to be further analysed according to the real-time physiological responses.

Seafarers tend to be in vulnerable possession when manoeuvring in bridge simulator. Conducting the psychophysiology research in bridge simulator is a meaningful study on human factors or human errors in maritime operations. In addition, the bridge simulation benefits researches on human factors, especially for crew training requirement. From these perspectives, further studies will involve psychophysiological methods to measure seafarers' state and performance in real-time bridge simulation.

\section{ACKNOWLEDGEMENTS}

The research was supported by the National Science Foundation of China (NSFC) under grant No. 51609194, the National Key Technologies Research \& Development Program (2017YFC080490, 2017 YFC0804904), and the Fundamental Research Funds for the Central Universities (WUT: 2017IVA102, 
2017IVB049, 2017IVB074). The authors would like to thank the University of Florida for sharing the IADS database. The authors also appreciate the support of China MSA, the Bridge Simulator centre in Wuhan University of Technology, and all bridge officers participated in this experiment.

\section{REFERENCES}

AGUIAR, Y. P. C., VIEIRA, M. D. Q., GALY-MARIE, E. \& SANTONI, C. 2015. Analysis of the User Behaviour When Interacting with Systems During Critical Situations. In: MERCANTINI, J. M. \& FAUCHER, C. (eds.) Risk and Cognition. Berlin: Springer-Verlag Berlin.

AKHTAR, M. J. \& UTNE, I. B. 2015. Common patterns in aggregated accident analysis charts from human fatigue-related groundings and collisions at sea. Maritime Policy \& Management, 42, 186-206.

AKYUZ, E. \& CELIK, M. 2015. Application of CREAM human reliability model to cargo loading process of LPG tankers. Journal of Loss Prevention in the Process Industries, 34, 39-48.

BRADLEY, M. M. \& LANG, P. J. 1994. Measuring emotion: The self-assessment manikin and the semantic differential. Journal of Behavior Therapy and Experimental Psychiatry, 25, 49-59.

BRADLEY, M. M. \& LANG, P. J. 2007. The International Affective Digitized Sounds (2nd Edition; IADS-2): Affective ratings of sounds and instruction manual. Technical report B-3. University of Florida, Gainesville, Fl.

CELIK, M. \& CEBI, S. 2009. Analytical HFACS for investigating human errors in shipping accidents. Accident Analysis and Prevention, 41, 66-75.

CHAUVIN, C., LARDJANE, S., MOREL, G., CLOSTERMANN, J. P. \& LANGARD, B. 2013. Human and organisational factors in maritime accidents: Analysis of collisions at sea using the HFACS. Accident Analysis and Prevention, 59, 26-37.

CHEN, S. T., WALL, A., DAVIES, P., YANG, Z. L., WANG, J. \& CHOU, Y. H. 2013. A Human and Organisational Factors (HOFs) analysis method for marine casualties using HFACS-Maritime Accidents (HFACS-MA). Safety Science, 60, 105-114.

ER, Z. \& CELIK, M. 2005. Definitions of human factor analysis for the maritime safety management process.

GEETHANJALI, B., ADALARASU, K., HEMAPRABA, A., KUMAR, S. P. \& RAJASEKERAN, R. 2017. Emotion analysis using SAM (Self-Assessment Manikin) scale. Biomedical Research.

GRECH, M. R., HORBERRY, T. \& KOESTER, T. 2008. Human factors in the maritime domain.

HETHERINGTON, C., FLIN, R. \& MEARNS, K. 2006. Safety in shipping: The human element. Journal of Safety Research, 37, 401-411.

LIU, Y., HOU, X., SOURINA, O., KONOVESSIS, D. \& KRISHNAN, G. 2016a. EEG-based human factors evaluation for maritime simulator-aided assessment: Proceedings of the 3rd International Conference on Maritime Technology and Engineering (MARTECH 2016, Lisbon, Portugal, 4-6 July 2016).

LIU, Y. S., HOU, X. Y., SOURINA, O., KONOVESSIS, D. \& KRISHNAN, G. 2016b. Human factor study for maritime simulator-based assessment of cadets, New York, Amer Soc Mechanical Engineers.

LUTZHOFT, M. H. \& DEKKER, S. W. A. 2002. On your watch: Automation on the bridge. Journal of Navigation, 55, 83-96.

REN, J., JENKINSON, I., WANG, J., XU, D. L. \& YANG, J. B. 2008. A methodology to model causal relationships on offshore safety assessment focusing on human and organizational factors. Journal of Safety Research, 39, 87-100.

SONER, O., ASAN, U. \& CELIK, M. 2015. Use of HFACSFCM in fire prevention modelling on board ships. Safety Science, 77, 25-41.

YANG, Z. L., BONSALL, S., WALL, A., WANG, J. \& USMAN, M. 2013. A modified CREAM to human reliability quantification in marine engineering. Ocean Engineering, 58, 293-303.

YANG, Z. L. \& WANG, J. 2012. Quantitative retrospective analysis of CREAM in maritime operations.

YOSHIMURA, K., TAKEMOTO, T., MITOMO, N. \& IEEE 2015. The Support for using the Cognitive Reliability and Error Analysis Method (CREAM) for Marine Accident Investigation. 2015 4th International Conference on Informatics, Electronics \& Vision Iciev 15 . 